\title{
Follow-up Study of the Heart in Acromegaly: Pre- and Post-operative Evaluation
}

\author{
Keiji IIDA, Yoshinobu KoIDE, Yasuro SUgISHITA, Mitsuo MATSUdA, \\ Kouichi KAWAI, Kimihiko YUKISADA, Yuji TOMONO, \\ Kamejiro YAMASHITA and Iwao ITO
}

\begin{abstract}
Pre-operative and post-operative echocardiographic data were analyzed from 8 patients with acromegaly. Pre-operatively, end-diastolic diameter was greater than $55 \mathrm{~mm}$ in 5 patients $(63 \%)$ and concentric left ventricular hypertrophy was observed in 3 patients $(38 \%)$. However, left ventricular function was normal (fractional shortening of the left ventricle $\mathbf{> 2 8} \%$ ) in all patients except 1 . All patients had increased left ventricular mass. There was no significant correlation between left ventricular mass and basal plasma growth hormone concentration. An average of $\mathbf{2 3 . 9}$ months after hypophysectomy, growth hormone concentration was significantly decreased. However, the abnormal echocardiographic findings remained. In conclusion, echocardiographic abnormalities (left ventricular dilatation and hypertrophy) are common in patients with acromegaly, but systolic function is, in general, maintained. These cardiac abnormalities persist after reduction of plasma growth hormone concentration.
\end{abstract}

Key words: Left ventricular hypertrophy, Left ventricular dilatation, Systolic function, Hypophysectomy

Visceromegaly, including cardiomegaly is a common finding in acromegaly (1-14). Because cardiovascular diseases were reported to be the most frequent cause of death in acromegalic patients (15), it is important to assess cardiac anatomy and function in such patients. These factors have been considered in several papers on cardiac anatomy and function in acromegaly (2-14). Although several investigators emphasized the importance of followup study of cardiac findings $(8-10,12,13)$, the effect of reduction of growth hormone by hypophysectomy on cardiac anatomy and function remains to be clarified.

The development of echocardiography has offered a simple and noninvasive method of evaluating myocardial structure and function. The size, wall thickness, contraction and muscle mass of the left ventricle can be evaluated. We have, therefore, studied a group of acromegalic patients, using echocardiography to assess cardiac anatomy and function before and after the reduction of growth hormone by hypophysectomy.

\section{MATERIALS AND METHODS}

\section{Patients}

Eight acromegalic patients were studied. Clinical data of the patients are summarized in Table 1. The diagnosis of acromegaly was established by clinical features and demonstration of an elevated basal growth hormone level which was not suppressed below $10 \mathrm{ng} / \mathrm{ml}$ by oral administration of 50 or 75 $\mathrm{g}$ of glucose. The study group consisted of 6 men and 2 women, with ages ranging from 31 to 53 years (mean age 46 years). All patients underwent hypophysectomy. Post-operative evaluation was performed an average of 23.9 (range 9-34) months

From Divisions of Cardiology and Endocrinology, Department of Internal Medicine, Institute of Clinical Medicine, University of Tsukuba, Tsukuba

Received for publication July 6, 1989; Accepted for publication January 11, 1990

Reprint requests should be addressed to Yasuro Sugishita, MD, Department of Internal Medicine, Institute of Clinical Medicine, University of Tsukuba, Tsukuba 305, Japan 
Table 1. Patient profiles before and after hypophysectomy.

\begin{tabular}{|c|c|c|c|c|c|c|c|c|c|c|c|}
\hline \multirow[t]{2}{*}{$\begin{array}{c}\text { Patient } \\
\text { age }\end{array}$} & \multirow[t]{2}{*}{ sex } & \multirow{2}{*}{$\begin{array}{l}\text { Estimated } \\
\text { duration of } \\
\text { acromegalic } \\
\text { state (years) }\end{array}$} & \multirow{2}{*}{$\begin{array}{l}\text { Interval between } \\
\text { pre- and } \\
\text { post-operative } \\
\text { studies (months) }\end{array}$} & \multicolumn{2}{|c|}{ B H $(\mathrm{cm})$} & \multicolumn{2}{|c|}{ B W (kg) } & \multicolumn{2}{|c|}{$\operatorname{BSA}\left(\mathrm{m}^{2}\right)$} & \multicolumn{2}{|c|}{$\begin{array}{c}\text { plasma G H level } \\
(\mathrm{ng} / \mathrm{ml})\end{array}$} \\
\hline & & & & Pre-op & Post-op & Pre-op & Post-op & Pre-op & Post-op & Pre-op & Post-op \\
\hline 1. 51 & $\mathrm{M}$ & 15 & 34 & 167 & 167 & 71 & 63 & 1.80 & 1.71 & 34 & 3.4 \\
\hline 2. 43 & M & 22 & 16 & 172 & 170 & 73 & 60 & 1.86 & 1.70 & 50 & 5.0 \\
\hline 3. 49 & M & 16 & 27 & 167 & 167 & 71 & 73 & 1.80 & 1.82 & 60 & 3.3 \\
\hline 4. 45 & M & 10 & 35 & 161 & 161 & 58 & 64 & 1.61 & 1.67 & 45 & 2.1 \\
\hline 5. 45 & M & 25 & 26 & 160 & 160 & 67 & 70 & 1.70 & 1.73 & 35 & 3.9 \\
\hline 6. 31 & $\mathrm{~F}$ & 15 & 26 & 169 & 169 & 75 & 77 & 1.86 & 1.88 & 17 & 1.8 \\
\hline 7. 53 & $\mathrm{M}$ & 20 & 9 & 152 & 152 & 64 & 58 & 1.61 & 1.54 & 66 & 4.8 \\
\hline 8. 53 & $\mathrm{~F}$ & 10 & 18 & 157 & 157 & 72 & 68 & 1.73 & 1.69 & 32 & 8.0 \\
\hline mean & 46.3 & 16.6 & 23.9 & 163.1 & 162.9 & 68.9 & 66.6 & 1.74 & 1.72 & 42.4 & 4.0 \\
\hline \multirow[t]{2}{*}{$\mathrm{SE}$} & 6.7 & 5.0 & 3.0 & 2.4 & 2.3 & 2.0 & 2.3 & 0.04 & 0.04 & 5.7 & 0.7 \\
\hline & & & & \multicolumn{2}{|c|}{$\mathrm{ns}$} & \multicolumn{2}{|c|}{ ns } & \multicolumn{2}{|c|}{ ns } & \multicolumn{2}{|c|}{$\mathrm{p}<0.001$} \\
\hline
\end{tabular}

BH: body height, BW: Body weight, BSA: body surface area, GH: growth hormone, SE: standard error, ns: not significant

after the operation.

\section{Echocardiographic studies}

Complete echocardiographic studies were performed in all patients using a Toshiba SSH-11A with a $2.4 \mathrm{MHz}$ transducer focused at $7.5 \mathrm{~cm}$. Echocardiograms were obtained from all patients in either supine or partial left lateral decubitus position. The transducer was placed on the third or fourth left intercostal space at the left sternal edge. Left ventricular echocardiograms were recorded at the level of the chordae tendineae just below the tips of the mitral leaflets under monitoring by twodimensional echocardiography. The recordings were made with a Honeywell 1219 strip-chart recorder at a paper speed of $50 \mathrm{~mm} / \mathrm{s}$. Electrocardiograms and phonocardiograms were also recorded. Left ventricular end-diastolic diameter (EDD) was determined at the $\mathrm{R}$ wave of the electrocardiogram, and endsystolic diameter (ESD) was determined at the time of the second heart sound of the phonocardiogram. Fractional shortening (FS, \%) was obtained by $($ EDD-ESD) $/ E D D \times 100$. Interventricular septal thickness (IVST) and left ventricular posterior wall thickness (PWT) were measured at the $\mathrm{R}$ wave of the electrocardiogram. Left ventricular mass (LVM) was calculated using the following formula: LVM $(\mathrm{g})=1.04 \times\left[(\mathrm{EDD}+\mathrm{IVST}+\mathrm{PWT})^{3}-\mathrm{EDD}^{3}\right]-14$ (16).

Paired Student's t-test was used to compare the changes produced by hypophysectomy. The relationships between variables were examined by linear regression analysis. Statistical significance was defined as $\mathrm{p}<0.05$.

\section{RESULTS}

\section{Pre-operative evaluation}

Six patients (Cases 1, 3, 4, 5, 7 and 8) had a history of hypertension, which was defined as blood pressure greater than $160 / 95 \mathrm{mmHg}$. However, their blood pressure had been maintained in a normal range for several years and no patients had hypertension at the time of the study. As shown in Table 1, basal plasma growth hormone levels at the time of echocardiography ranged from 17 to $66 \mathrm{ng} / \mathrm{ml}$ (mean $=42.4 \pm 5.7 \mathrm{ng} / \mathrm{ml}$, mean \pm standard error (SE)). Hyperglycemia was observed in 2 patients (Cases 3 and 4), being especially severe in Case 3; and impaired glucose tolerance, in 2 patients (Cases 7 and 8). Hypercholesterolemia was not observed in any patients. Hypertriglyceridemia was observed in 3 patients (Cases 3, 5 and 7).

Echocardiographic findings before hypophysectomy are summarized for all 8 patients in Table 2. In 5 patients (Cases 1, 2, 3, 6 and 8) (75\%), EDD was greater than $55 \mathrm{~mm}$ (normal range: 39-54 $\mathrm{mm}$ ). FS was normal in all patients but 1 (Case 3) (normal range: 28-44\%). In 5 patients (Cases 1, 2, 3,4 and 8 ) the IVST was equal to or greater than 
Table 2. Echocardiographic data before and after hypophysectomy.

\begin{tabular}{|c|c|c|c|c|c|c|c|c|c|c|c|c|}
\hline \multirow[t]{2}{*}{ Patient } & \multicolumn{2}{|c|}{$\mathrm{EDD}(\mathrm{mm})$} & \multicolumn{2}{|c|}{ F S $(\%)$} & \multicolumn{2}{|c|}{ IVST (mm) } & \multicolumn{2}{|c|}{ PWT (mm) } & \multicolumn{2}{|c|}{ LVM (g) } & \multicolumn{2}{|c|}{ LVM index $\left(\mathrm{g} / \mathrm{m}^{2}\right)$} \\
\hline & Pre-op & Post-op & Pre-op & Post-op & Pre-op & Post-op & Pre-op & Post-op & Pre-op & Post-op & Pre-op & Post-op \\
\hline 1. & 58 & 60 & 36 & 32 & 12 & 12 & 12 & 12 & 357 & 378 & 198 & 221 \\
\hline 2. & 62 & 60 & 37 & 33 & 12 & 12 & 11 & 12 & 377 & 378 & 203 & 222 \\
\hline 3. & 63 & 76 & 5 & 5 & 12 & 9 & 11 & 9 & 356 & 393 & 198 & 216 \\
\hline 4. & 45 & 45 & 36 & 38 & 12 & 12 & 13 & 12 & 248 & 233 & 154 & 140 \\
\hline 5. & 52 & 50 & 48 & 50 & 11 & 11 & 11 & 11 & 261 & 234 & 154 & 135 \\
\hline 6. & 64 & 59 & 34 & 34 & 10 & 10 & 11 & 11 & 352 & 305 & 189 & 162 \\
\hline 7. & 51 & 49 & 39 & 43 & 10 & 10 & 11 & 11 & 236 & 220 & 147 & 143 \\
\hline 8. & 57 & 54 & 39 & 37 & 12 & 13 & 13 & 10 & 326 & 297 & 188 & 176 \\
\hline mean & 56.5 & 55.5 & 34.3 & 34.0 & 11.4 & 11.1 & 11.6 & 11.6 & 314.1 & 304.8 & 178.9 & 176.9 \\
\hline \multirow[t]{2}{*}{ SE } & 2.4 & 3.7 & 4.4 & 4.6 & 0.3 & 0.5 & 0.3 & 0.5 & 20.0 & 25.3 & 8.2 & 13.4 \\
\hline & \multicolumn{2}{|l|}{ ns } & \multicolumn{2}{|c|}{ ns } & \multicolumn{2}{|c|}{ ns } & \multicolumn{2}{|c|}{ ns } & \multicolumn{2}{|c|}{ ns } & \multicolumn{2}{|c|}{$\mathrm{ns}$} \\
\hline
\end{tabular}

EDD: left ventricular end-diastolic diameter, FS: fractional shortening, IVST: interventricular septal thickness, PWT: left ventricular posterior wall thickness, LVM: left ventricular mass, SE: standard error, ns: not significant

$12 \mathrm{~mm}$ (normal range $6-11 \mathrm{~mm}$ ). In 3 patients (Cases 1, 4 and 8), the PWT was equal to or greater than $12 \mathrm{~mm}$ (normal range: $7-11 \mathrm{~mm}$ ). Three patients (Cases 1, 4 and 8) had echocardiograms consistent with concentric left ventricular hypertrophy (i.e., both the IVST and PWT were greater than 11 $\mathrm{mm}$ but the septal: posterior wall thickness ratio was $<1.3)$. The means $\pm \mathrm{SE}$ of their IVST and PWT were $11.4 \pm 0.3 \mathrm{~mm}$ (range $=10-12 \mathrm{~mm}$ ) and $11.6 \pm 0.3 \mathrm{~mm}$ (range $=11-13 \mathrm{~mm}$ ), respectively. An increased LVM and LVM index were observed in all patients (normal range; $80-200 \mathrm{~g}, 45-105$ $\mathrm{g} / \mathrm{m}^{2}$, respectively). Left ventricular changes did not correlate with age or estimated duration of the acromegalic state. There was also no correlation between the degree and/or duration of hypertension and left ventricular changes. There was no significant correlation between LVM and basal plasma growth hormone level (Fig. 1). Case 3, who had severely depressed left ventricular function (FS: 5\%), had severe hyperglycemia. Hypertriglyceridemia was not related to left ventricular changes.

\section{Effects of hypophysectomy}

Effects of hypophysectomy on clinical and echocardiographic findings were studied about 2 years ( $23.9 \pm 2.8$ months) after the operation. Body weight decreased in 4 patients (Cases 1, 2, 7 and 8) and increased in 4 patients (Cases 3, 4, 5 and 6) after

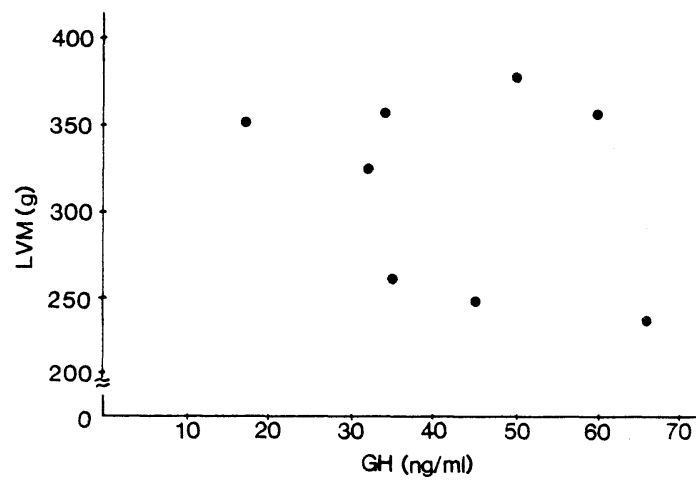

Fig. 1. The relationship between left ventricular mass (LVM) and basal plasma growth hormone level $(\mathrm{GH})$ in patients with acromegaly.

surgery. Blood pressure was maintained in a normal range in all 8 patients post-operatively. Basal plasma growth hormone level was reduced to the normal range (less than $5 \mathrm{ng} / \mathrm{ml}$ ) in 7 patients, and its mean level was $4.0 \pm 0.7 \mathrm{ng} / \mathrm{ml}$, which was significantly lower than that before the operation $(p<0.001)$ (Table 1, Fig. 2). The degree of hyperglycemia was unchanged in 2 patients (Cases 3 and 4), but the impaired glucose tolerance in 2 other patients (Cases 7 and 8) normalized. Hypertriglyceridemia in 3 patients (Cases 3, 5 and 7) normalized after surgery.

However, no echocardiographic parameters showed significant changes (EDD: $56.5 \pm 2.4$ to $55.5 \pm 3.7 \mathrm{~mm}$, IVST: $11.4 \pm 0.3$ to $11.1 \pm 0.5 \mathrm{~mm}$, 


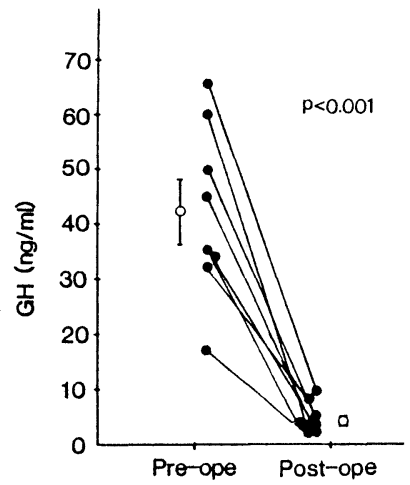

Fig. 2. Basal plasma growth hormone levels $(\mathrm{GH})$ before (Pre-op) and after (Post-op) hypophysectomy.

PWT: $11.6 \pm 0.3$ to $11.0 \pm 0.5 \mathrm{~mm}$, FS: $34.3 \pm 4.4$ to $34.0 \pm 4.6 \%$ ) (Table 2). In the patient (Case 3 ), who pre-operatively showed left ventricular dilatation and severe left ventricular dysfunction with severe hyperglycemia, there was progressive left ventricular dilatation (EDD: 63 to $76 \mathrm{~mm}$ ) and heart failure, 27 months after surgery.

\section{DISCUSSION}

The present study was designed to echocardiographically evaluate cardiac anatomy and function in acromegaly as well as the effects of reduction in plasma growth hormone levels following hypophysectomy. The pre-operative echocardiographic measurement showed increased EDD in 5 of 8 patients, concentric left ventricular hypertrophy in 3 patients and increased LVM in all patients. In spite of ventricular dilatation and hypertrophy, left ventricular function was good in general, except in 1 patient (Case 3 ) with left ventricular dilatation, as demonstrated in previous studies (8-12).

The pathophysiologic mechanism by which left ventricular dilatation and left ventricular hypertrophy occur in acromegalic patients is obscure. One hypothesis is that the cardiac lesion is closely related to an increased growth hormone concentration. This could be due to; (1) increased work demand due to somatomegaly, (2) direct effects of growth hormone on cardiac muscle, or (3) other growth hormonerelated mechanisms.

Left ventricular dilatation and well maintained left ventricular function mean an increase in cardiac output which is not typical of an idiopathic dilated cardiomyopathy. This observation, therefore, suggests that left ventricular dilatation occurred as a result of increased work demand to meet the metabolic and growth requirements induced by generalized splanchnomegaly and somatomegaly. However, some patients in active acromegaly did not show left ventricular dilatation. Moreover, cardiac abnormalities persisted after hypophysectomy when plasma growth hormone significantly decreased and work demand was expected to decrease or normalize. Therefore, it is not reasonable to ascribe left ventricular dilatation only to an increased work demand due to somatomegaly.

Marked cardiac hypertrophy was elicited, even in the presence of subnormal blood pressure, by experimental administration of growth hormone to rats (17). Korner reviewed the anabolic action of growth hormone and attributed increased protein synthesis to it (18). These findings might endorse the hypothesis that growth hormone produces cardiac lesions directly, rather than through hypertension, and/or increased work demand. Our study demonstrated no significant correlation between basal plasma growth hormone level and LVM, which is consistent with the data from previous studies $(4,8,10)$. However, our results do not necessarily deny the direct action of growth hormone on cardiac muscle. For example, there are several possible explanations for the lack of correlation between echocardiographic findings and growth hormone levels: (1) even a small increase in growth hormone may be enough to produce cardiac hypertrophy; (2) somatomedin-C, which mediates the effect of growth hormone, might correlate with cardiac changes better than growth hormone; (3) basal growth hormone level in the morning demonstrated in the present study might not represent growth hormone activity throughout the day; (4) immunologically determined growth hormone levels do not necessarily correlate with those of biologically intact growth hormone; and (5) hormonal disturbances associated with growth hormone excess might mediate its direct effects on the myocardium.

Despite marked and significant reduction of growth hormone, echocardiographic parameters did not show significant changes, even in the 7 patients whose plasma growth hormone level was reduced 
to the normal range (less than $5 \mathrm{ng} / \mathrm{ml}$ ). Pepine and Aloia described an acromegalic patient with severe heart failure, who showed an improvement in exercise tolerance and reduction in heart size after hypophysectomy (3). However, the size of his heart had already decreased before the operation. Therefore, the amelioration of the cardiac status might be ascribed to factors other than the reduction in plasma growth hormone levels, i.e., medication and/or bed rest. On the other hand, a patient whose heart size increased after the treatment (needle implantation of radioactive seed into the pituitary tumor) was reported (14). In the present study, one patient (Case 3) with marked left ventricular dilatation and hypokinesia before surgery showed progressive left ventricular dilatation even after hypophysectomy. One explanation for this deterioration might be severe diabetes mellitus. The other metabolic factors, such as plasma cholesterol, triglyceride and body weight were unrelated to left ventricular status and its course after surgery.

Myocardial changes induced by mechanical factors, for example, aortic stenosis or aortic regurgitation, were demonstrated by echocardiographic and angiographic techniques to be significantly improved within 6 months of removal of the load (aortic valve replacement) $(19,20)$. This contrasts with the lack of improvement in acromegalic patients after treatment. Histological examination of the myocardium in patients with acromegaly have shown an increase in fibrous connective tissue $(2,7,11)$. Such changes induced by the metabolic disorders could be one of the mechanisms leading to less reversibility of myocardial changes in acromegaly. Longer follow-up study will be needed to assess the course of myocardial changes in acromegaly.

ACKNOWLEDGEMENT: This work was supported by Grants from the Japanese Ministry of Health and Welfare for the study of idiopathic cardiomyopathy.

\section{REFERENCES}

1) Courville $C$, Mason VR. The heart in acromegaly. Arch Intern Med 61: 704, 1983.

2) Hejtmaink MR, Bradfield JR, Herrmann GR.
Acromegaly and the heart: A clinical and pathological study. Ann Intern Med 48: 1445, 1951.

3) Pepine CJ, Aloia J. Heart muscle disease in acromegaly. Am J Med 48: 530, 1970.

4) McGuffin WL, Sherman BM, Roth J, et al. Acromegaly and cardiovascular disorder. Ann Intern Med 81: 11, 1974.

5) Martins JB, Kerber RE, Sherman BM, Marcus ML, Ehrhadt JC. Cardiac size and function in acromegaly. Circulation 56: 863, 1977.

6) Jone EA, Alois JF, Lane JL. Evidence of subclinical heart muscle dysfunction in acromegaly. Chest 67: 190, 1975.

7) Rossi L, Thiene G, Caregaro L, Giordano R, Lauro S. Dysrhythmias and sudden death in acromegalic heart disease. Chest 72: 495, 1977.

8) Mather HM, Boyd MJ, Jenkins JS. Heart size and function in acromegaly. Br Heart J 41: 697, 1979.

9) Smallride RC, Rajfer S, Davia J, Schaaf M. Acromegaly and the heart. Am J Med 66: 22, 1979.

10) Savage DD, Henry WL, Eastman RC, Borer JS, Gorden P. Echocardiographic assessment of cardiac anatomy and function in acromegalic patients. Am J Med 67: $823,1979$.

11) Lie JT, Grossman SJ. Pathology of the heart in acromegaly: Anatomic findings in 27 autopsied patients. Am Heart J 100: 41, 1980.

12) O'Keefe JC, Grant SJ, Wiseman JC, et al. Acromegaly and the heart. Echocardiographic and nuclear imaging studies. Aust NZ J Med 12: 603, 1982.

13) Csanady M, Gasper L, Hogye M, Gruber N. The heart in acromegaly: An echocardiographic study. Int J Cardiol 2: 349, 1983.

14) Clinicopathological conference. A case of acromegalic heart disease. Br Med J 1: 718, 1973.

15) Wright AD, Hill DM, Lowy C, Fraser TR. Mortality in acromegaly. Q J Med (New Series) 39: 1, 1970.

16) Devereux RB, Reichek N. Echocardiographic determination of left ventricular mass in man. Anatomic validation of the method. Circulation 55: 613, 1977.

17) De Grandpre R, Raab W. Interrelated hormonal factors in cardiac hypertrophy. Experiments in nonhypertensive hypophysectomized rats. Circ Res 1: 345, 1953.

18) Korner A. Anabolic action of growth hormone. Ann NY Acad Sci 148 (Part 2): 408, 1968.

19) Pantely G, Morton M, Rahimtoola SH. Effects of successful, uncomplicated valve replacement on ventricular hypertrophy, and performance in aortic stenosis and aortic incompetence. J Thorac Cardiovasc Surg 75: 383, 1978.

20) Henry WL, Bonow RO, Borer JS, et al. Evaluation of valve replacement in patients with valvular aortic stenosis. Circulation 61: 814, 1980. 